\title{
Visualisation of a mathematical model of blast furnace operation for distance learning purposes
}

\author{
A. Babich*, D. Senk*, H.W. Gudenau*, K. Mavrommatis*, O. Spaniol**, Y. Babich** \\ and A. Formoso ${ }^{* * *}$
}

\begin{abstract}
Advanced educational technologies like Virtual Laboratories are being developed and launched in order to equip customers from higher education institutions, research and industry with efficient tools, supporting their work and operating new skills-training methods. Visual Model "Blast Furnace" based on a mathematical balance model of the blast furnace process has been developed for distance learning (DL) purposes. It processes entered parameters and outputs both operating and learning results. The model simulates also sinter and pellets manufacture as well as operation of hot stove. The teacher and learners can interact with each other using software interface which allows to monitor the activity of the learners, answer their questions, and analyse the learning results. The model is an ingredient of the "Virtual Lab Ironmaking".
\end{abstract}

Keywords Visual model. Blast furnace. Online simulation. Distance learning. Virtual laboratory

\section{Visualización de un modelo matemático de la operación del horno alto con el objetivo de la enseñansa a distancia}

Resumen Se desarrollan y presentan tecnologías avanzadas de educación, como los Laboratorios Virtuales, para suministrar a los clientes de las instituciones de educación superior, investigación e industria, en apoyo de su trabajo, nuevos y eficientes métodos de operación y técnicas especiales de adiestramiento. Se ha desarrollado el Modelo Visual de "Horno Alto" basado en un modelo matemático del balance del proceso del horno alto, para fines de educación a distancia. Procesa los parámetros de entrada y salida en operación y los resultados de la enseñanza. El modelo también simula la fabricación de sínter y pelets, además de la operación de las estufas. El profesor y alumnos pueden interactuar entre sí usando un software que permite seguir la marcha de la actividad de los alumnos, responder a sus preguntas y analizar los resultados del aprendizaje. El modelo es parte del "Laboratorio Virtual de Fabricación de Arrabio".

Palabras clave Modelo visual. Horno alto. Simulación en línea. Enseñanza a distancia. Laboratorio virtual.

\section{INTRODUCTION}

DL is a form of learning in which a learner communicates with a learning technology system or teacher via a network. In the past few years we saw a rapid growth in the number of higher education institutions offering courses for DL. The main reason is the usage of computers, graphical user interfaces, and the Internet for this purpose, bringing the term "e-learning" to the world.

Not only customers from higher education institutions but also other target groups such as personnel and trainees involved in vocational training, professionals in research and industry are interested in new high quality products of e-learning resources and tools. Steel companies

$\left.{ }^{*}\right)$ Dept. of Ferrous Metallurgy, Aachen University, Germany.

$\left(^{* *}\right)$ Dept. of Computer Science IV, Aachen University, Germany.

$\left(^{* * *}\right)$ National Center for Metallurgical Research, Madrid, Spain 
have a multitude of training needs. As technical processes continue to change, employees must keep up with advances in technology. Lifelong learning becomes a reality. Some companies play both the role of a customer and the role of the educational content provider. E.g. Arcelor group develops the knowledge based systems to improve business performance $^{[1]}$.

Modelling of complicated technological processes, phenomena and equipment is one of the important means of their investigation, control, prediction as well as of better understanding, further improvement and training ${ }^{[2-4]}$.

Blast furnace process is a good example of a complicated technological processes. It is characterised by numerous physical, chemical, physico-chemical, mechanical and hydraulic processes, homo- and heterogeneous reactions which occur simultaneously and affect each other. The peculiarities of the blast furnace process as modelling and control object are:

- interconditionality: close correlation of air and gas dynamic, heat and mass exchange processes; every output variable depends on a multitude of input variables;

- non-linearity of relations;

- inertia and non-stationarity;

- big transport delays during control from the top;

- difficulty of identification;

- ambiguity and losses of information: it is possible to generate two different sets of inputs which are adequate to the given set of outputs.

This paper is focused on an interactive visual model of the blast furnace process which has been developed at the Aachen University for remote studies and has proved its usability and fitness within the scope of the EU Project for PanEuropean Higher Education UNIVERSAL. It helps training and testing learning success at the example of blast furnace ironmaking.

\section{BASE MATHEMATICAL MODEL}

A mathematical model of the blast furnace process. was developed at the Donetsk National Technical University, Ukraine ${ }^{[5]}$ and shortly described $i^{[6]}$. This is a total balance model that does not require any input parameters to be assumed.

The model was developed on the base of a method of Prof. A.N. Ramm ${ }^{[7]}$. This method is based on the interrelations of material and heat balances equations. Its characteristic feature is the following: a system of equations of material balance of different input components according to which a target hot metal chemical composition is formed; to this system one equation of heat balance is added which determines the correlation between coke rate and remaining components. The coke rate is introduced as unknown value in all equations of the material balance, rates of iron bearing and flux components in the heat balance equation.

Main balance equations are written in generic form as follows:

Hot metal output: $\quad \mathrm{i} \cdot \mathrm{e}_{\mathrm{i}}+\mathrm{f} \cdot \mathrm{e}_{\mathrm{f}}+\mathrm{c} \cdot \mathrm{e}_{\mathrm{c}}+\mathrm{s} \cdot \mathrm{e}_{\mathrm{s}}=1$ Slag basicity: $\quad \mathrm{i} \cdot \mathrm{RO}_{\mathrm{i}}+\mathrm{f} \cdot \mathrm{RO}_{\mathrm{f}}+\mathrm{c} \cdot \mathrm{RO}_{\mathrm{c}}+\mathrm{s} \cdot \mathrm{RO}_{\mathrm{s}}=0$ Heat balance: $\quad i \cdot q_{i}+f \cdot q_{f}+c \cdot q_{c}+s \cdot q_{s}=1$

"Excessive" amount of an element in hot metal:

$$
i \cdot X_{i}+f \cdot X_{f}+c \cdot X_{c}+s \cdot X_{s}=0
$$

"Excessive" amount of an oxide in slag:

$$
\mathrm{i} \cdot Y_{\mathrm{i}}+\mathrm{f} \cdot \mathrm{Y}_{\mathrm{f}}+\mathrm{c} \cdot \mathrm{Y}_{\mathrm{c}}+\mathrm{s} \cdot \mathrm{Y}_{\mathrm{s}}=0
$$

where, i, f, c, s: consumption of iron bearing materials, flux, coke and injected substances respectively, $\mathrm{kg} / \mathrm{kgHM}$;

e: hot metal output per unit of corresponding material, $\mathrm{kg} / \mathrm{kg}$ material;

$\mathrm{q}$ : heat consumption, $\mathrm{kJ} / \mathrm{kg}\left(\mathrm{m}^{3}\right)$ material;

RO: "excessive" (unused) amount of bases in a given material at a given slag basicity, $\mathrm{kg} / \mathrm{kg}$ material;

X: "excessive" (unused) amount of element in a given material at a given content of this element in hot metal, $\mathrm{kg} / \mathrm{kg}$ material;

Y: "excessive" (unused) amount of oxide in a given material at a given content of this element in slag, $\mathrm{kg} / \mathrm{kg}$ material;

The key calculations in the method determine:

- amount of oxygen released during reduction

- injected substance characteristics: total quantity of $\mathrm{C}, \mathrm{H}, \mathrm{O}$ and $\mathrm{N}$; the enthalpy: heat released by burning in the raceway etc.

- volume of bosh gas

- direct reduction rate

- coke and total reducing agent consumption and blast volume

- flux consumption and slag volume

- top gas parameter (volume, temperature, composition, calorific value)

- heat balance (heat generated and absorbed) 
- flame temperature

- change in the productivity and intensity of the coke combustion.

The model was successfully used many times for optimisation of the performance of blast furnaces under different conditions and for forecast and development of new technologies ${ }^{[5 \text { and } 8-11]}$ but it is too complex to be used for learning or training purposes.

\section{VISUAL MODEL “BLAST FURNACE"}

The target of the visualisation of the mathematical model was to represent complicated blast furnace process visually and dynamically using the Internet for DL purposes.

The concept of the learning model is as follows. The complex mathematical description of the process and the basic mathematical model are invisible to a user. Learners only work with the relatively simple logic part (visual model), which is presented in form of a graphical user interface (Fig. 1). This part works in the way described below.

The model operation can be divided into several steps, each step requiring deeper understanding of the process. In the $1^{\text {st }}$ step values of individual parameters and the list of mandatory parameters are checked. When a wrong value of a parameter is entered or a mandatory parameter is not entered, an error message appears: corresponding parameters have to be entered or their values have to be changed. In the $2^{\text {nd }}$ step the

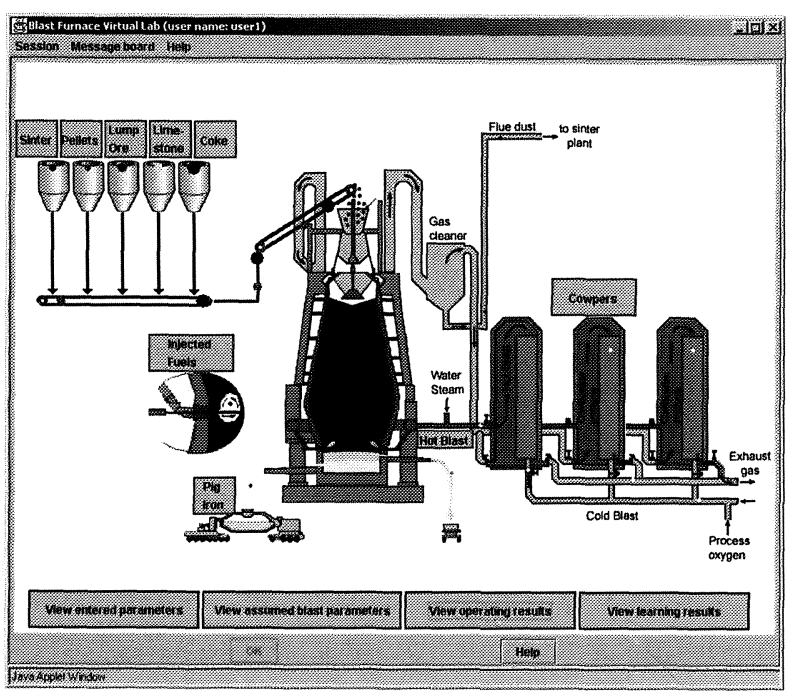

Figure 1. Screen shot of the Visual Model user interface.

Figura 1. Pantalla del Modelo Visual, interface para el usuario. combination of individual parameters is verified. In the $3^{\text {rd }}$ step total material and energy flows are examined and corresponding recommendations are given if necessary.

Wrong actions result in penalty points, which are accumulated and at the end affect the grade for process realisation.

Blast furnace is a link in the chain of metallurgical processes at integrated steel works. It consumes products of previous technological processes (sinter, pellets, coke ${ }^{[12]}$ ) as resources or raw materials and supplies products to further processes in this chain (hot metal for steelmaking). So a learner can either use ready raw materials or "produce" them using sub-models (Figs. 2 and 3), which operate in the same or similar way as the main mode (penalty points are added to those accumulated in the main model).

The second part of the work with the Simulation Model is the Process Control. It means that obtained operating results can be improved. Various modes to achieve this goal are foreseen: change of parameters in the main menu and choice of correction actions suggested by the model. Before making the decision about control actions, a student has the possibility to forecast change in value of some output parameters using an add-on calculation program (Fig. 4).

The model also reflects dynamics of the process (delay in the change of output parameters after conducting the control actions).

After completion of control actions Learning Results can be displayed. Grades for Process realisation and Process Control as well as a total grade are shown.

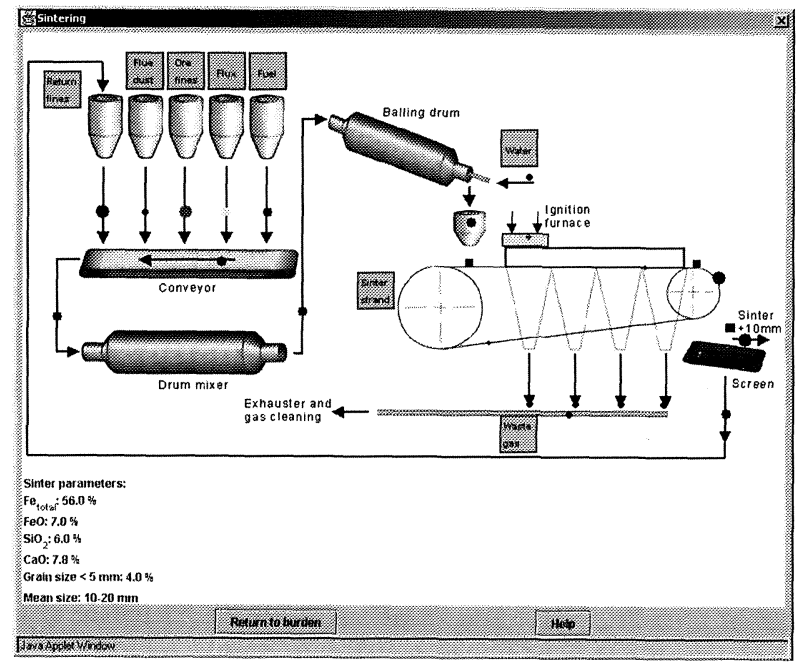

Figure 2. Sinter plant user interface.

Figura 2. Planta de sinter, interface usuario. 


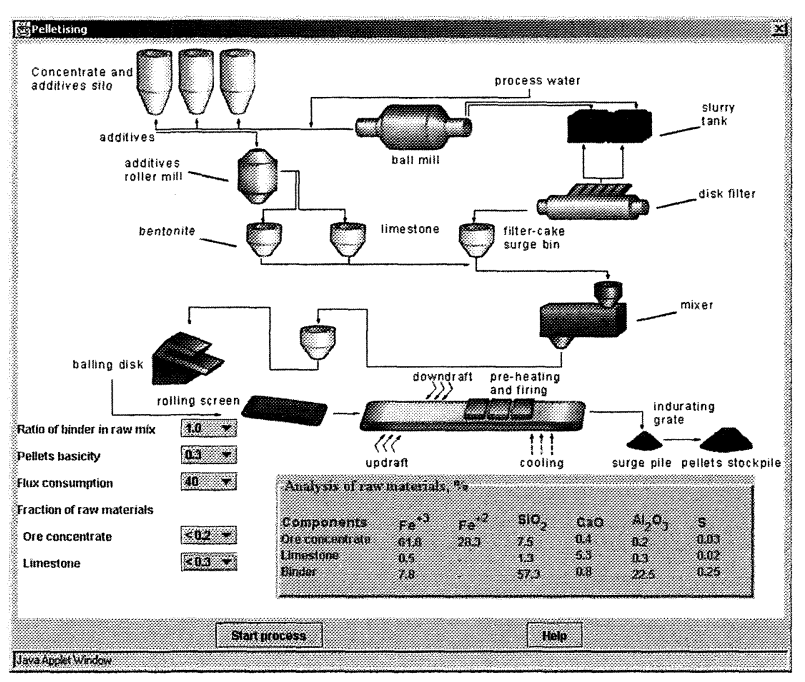

Figure 3. Pellet plant user interface.

Figura 3. Planta de pellets, interface usuario.

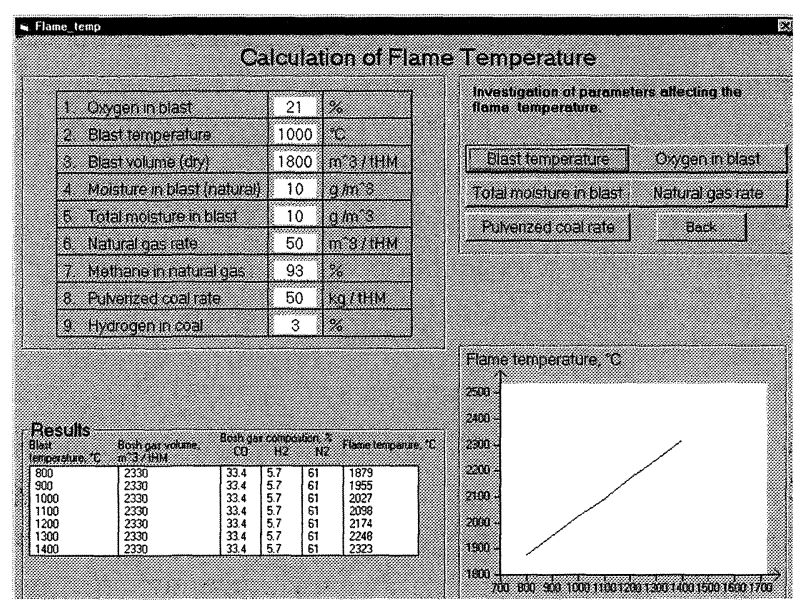

Figure 4. Screen shot of the program for investigation of parameters in the raceway zone.

Figura 4. Pantalla del programa para investigación de parámetros en la zona de soplo en toberas.

Tutor is provided with visual front-end software to monitor the activity of the students, answer their questions, and analyse the learning results. Students communicate with the tutor and with each other using a message board. The tutor can support students not only by means of this tool but also he can open each student's session and help the student directly. Collaborative work can also be carried out: several students on remote computers can together "charge" and "operate" the same blast furnace. For better analysis of student's work the tutor can view the log of all student's actions in the same order that they were done.

The software "Visual Model" is implemented in Java, thus being able to run on nearly any platform, and makes use of the Remote Method Invocation mechanism for communication over the Internet. The framework of the program is made quite general, so that on the one hand the underlying model or the user interface can be safely changed, and on the other hand models of entirely different metallurgical and other engineering processes can be easily added and integrated, given they conform to the programming interface.

\section{PERFORMING AND RESULTS OF ONLINE SIMULATION TRIAL}

Visual model is a constituent of the online course "Virtual Lab IRONMAKING". It includes further logically related components such as:

- video lecture "Ferrous Metallurgy - state of the art and prospects"

- on-line lecture textbooks "Raw Materials and Their Preparation", "Blast Furnace Process" and presentation "Direct and Smelting Reduction Processes"

- processing lab for investigation of process parameters in the raceway zone

- live video conference sessions broadcasting via the Internet

- interactive assessment tests.

The course was held firstly in the scope of the two-month Simulation Trial in April - May 2002 within the EU IST Project. The trial was organised and managed by the Dept. of Ferrous Metallurgy at the Aachen University.

Four higher education and research institutions took part in the trial and followed the whole course.

- National Centre for Metallurgical Investigations CENIM, Madrid, Spain

- Universidad Politécnica Madrid UPM, Spain

- Warsaw University of Technology WUT, Poland

- Aachen University RWTH Aachen, Germany

Swiss University ETH Zürich followed some parts of the course.

Altogether, there were 37 participants, including 25 students and postgraduates, 7 professors and teachers, and 5 experts in metallurgy.

The trial was successful. Pedagogical scenarios as well as the assessment procedure and results 
have been discussed in ${ }^{[12}$ and 13]. Simulation visual model "Blast Furnace" has been recognised as the most innovative course component. Work with the model included interactive sessions on the individual and group levels. International team work consisting in simultaneous control of one blast furnace by two or more remote participants have also been performed .

Presently the visual model is included in the practical course in the metallurgical education at the Dept. of Ferrous Metallurgy, Aachen University.

\section{CONCLUSIONS}

- Using mathematical methods, modelling and simulation of complicated technological processes and their representation in understandable visual way are of great importance in engineering study and especially for e-learning.

- A visual model of the blast furnace process for remote studies has been developed. It based on a mathematical balance model of the blast furnace process and allows to process entered parameters and to get both operating and learning results. The model simulates effect of the charge (coke and burden) and blast parameters on the blast furnace operation results: productivity, hot metal heat and quality, slag volume and basicity, top gas volume, chemistry and temperature, thermal state in the raceway, furnace driving and parameters of inner state.

- The model is one of the logically related components of the online course "Virtual Lab IRONMAKING". The usability and fitness of the course have been proved within the scope of a two month trial.

- The framework of the software "Visual Model" is made quite general, so that on the one hand the underlying model or the user interface can be safely changed, on the other hand models of entirely different processes can be easily added and integrated.

\section{Acknowledgements}

The authors wish to express thanks to Prof. J. Quemada, UPM for assistance in the organisation of video conference sessions and to the EU Commission for financial support in carrying out the simulation trial (IST Project No. 1999-11747).

\section{REFERENCES}

[1] J. FriGière, Stahl Eisen 122 (2002) 1-24.

[2] A. Babich, K. Mavrommatis and D. Senk, Proc. $18^{\text {th }}$ Aachen Steel Colloquium, 2003, Aachen, Germany, forthcoming.

[3] D. Ameling, Stahl Eisen 122 (2002) 23-31.

[4] C. Cantera, J. Jimenez, I. Varela and A. Formoso, Rev. Metal. Madrid 38 (2002) 243-248.

[5] S.L. YaroshevskiI, A.I. BABICH and G.N. SidorenKo, Methodical Instruction for Calculating Blast Furnace Operation Parameters, DPI, Donetsk, Ukraine, 1991, pp. $3-43$.

[6] A. Babich, H.W. Gudenau and K. Mavrommatis, C. Froehling, A. Formoso, A. Cores and L. Garcia, Rev. Metal. Madrid 38 (2002) 288-305.

[7] A.N. Ramm, A Modern Blast Furnace Process, Metallurgiya, Moscow, Russia, 1980, pp. 49-66.

[8] S.L. YAROSHEVSKII, A.I. BABICH and V.P. TERESHCHENKO, Stal' 8 (1995) 11-17.

[9] A. Babich, S. Yaroshevskil, L. Garcia, A. Formoso, A. CORES, A. IsIDRo and S. FerreirA, Rev. Metal. Madrid 32 (1996) 103-116.

[10] A. Babich, S. Yaroshevskil, A. Formoso, A. Isidro, S. FerreirA, A. Cores and L. GARCIA, ISIJ Int., 36 (1996) 1250-1258.

[11] Formoso, A. Cores, A. Babich, H.W. Gudenau, L. Garcia, S. YaroshevSKII and J.L.MEnÉndez, Rev. Metal. Madrid 37 (2001) 423-436.

[12] H.W. Gudenau, D. Senk, K. Fukada, A. Babich, C. Froehling, L.L. García, A. Formoso, FJ. Alguacil and A. Cores, Rev. Metal. Madrid, 39 (2003), 367-377.

[13] LAI-ChONG LAW and A. BABICH, Proc. 5th Int. Conf. New Educational Environment, 2003, Lucerne, Switzerland, forthcoming. 